\title{
Kinetics and Mechanism of Palladium(II)-Catalyzed Oxidation of Inositol by Hexachloroplatinate(IV) in Perchlorate Solutions
}

\author{
Ahmed Fawzy, 2, ", Ishaq A. Zaafarany ${ }^{1}$, Khalid S. Khairou ${ }^{1}$, Sheigha S. Ashour ${ }^{1}$, \\ Naeema Yarkandi ${ }^{1}$ \\ ${ }^{1}$ Chemistry Department, Faculty of Applied Science, Umm Al-Qura University, Makkah, Saudi Arabia \\ ${ }^{2}$ Chemistry Department, Faculty of Science, Assiut University, Assiut, Egypt
}

Email address:

afsaad13@yahoo.com (A. Fawzy), iazaafarany@uqu.edu.sa (I. A. Zaafarany), kskhairou@uqu.edu.sa (K. S. Khairou), sheikha_s_ashour@hotmail.com (S. S. Ashour),dr.naeema.y@gmail.com (N. Yarkandi)

*Corresponding author

\section{To cite this article:}

Ahmed Fawzy, Ishaq A. Zaafarany, Khalid S. Khairou, Sheigha S. Ashour, Naeema Yarkandi. Kinetics and Mechanism of Palladium(II)Catalyzed Oxidation of Inositol by Hexachloroplatinate(IV) in Perchlorate Solutions. American Journal of Applied Chemistry.

Vol. 4, No. 5, 2016, pp. 185-191. doi: 10.11648/j.ajac.20160405.15

Received: August 29, 2016; Accepted: September 8, 2016; Published: September 24, 2016

\begin{abstract}
Oxidation of inositol (INOS) by hexachloroplatinate(IV) complex (HCP) in perchlorate solutions in the presence of palladium(II) catalyst was studied spectrophotometrically. The reaction rate was very slow in the absence of the catalyst. The reaction exhibited a first order dependence on [HCP], and fractional-first order dependences with respect to [INOS], $\left[\mathrm{H}^{+}\right]$ and $[\operatorname{Pd}(\mathrm{II})]$. Increasing ionic strength and dielectric constant was found to increase the oxidation rate. A probable oxidation mechanism has been suggested and the rate-law expression has been derived. Both spectral and kinetic evidences revealed formation of a 1:1 intermediate complex between INOS and Pd(II) prior to the rate-controlling step. The final oxidation product of inositol was identified by both spectral and chemical analyses as the corresponding monoketone derivative, namely inosose. The activation parameters of the second order rate constant were evaluated and discussed.
\end{abstract}

Keywords: Inositol, Hexachloroplatinate(IV), Oxidation, Palladium(II), Kinetics, Mechanism

\section{Introduction}

Anticancer platinum(IV) complexes have attracted many researchers in the last decades [1-4]. Hexachloroplatinate(IV) complex is considered as one of the most important platinum(IV) complexes applicable to oxidize various organic and inorganic compounds in different media [2-15]. The kinetics and mechanism of antitumor activity of platinum(IV) compounds can be understood by investigating the reactivity of these compounds toward their reduction by bio-reductants such as amino acids [5-15].

Inositol is a water soluble six membered cyclic polyol, which is synthesized by both eukaryotes and prokaryote [16]. In humans most inositol is synthesized in the kidneys. Inositol and some of its mono and polyphosphates function as the basis for a number of signaling and secondary messenger molecules [17, 18]. These are involved in insulin signal transduction, gene expression, breakdown of fats and reducing blood cholesterol [19]. Oxidation of inositol was studied by different oxidants like alkaline potassium periodate [20], alkaline diperiodatocuprate(III) [21], alkalinepermanganate [22], $\mathrm{V}(\mathrm{V})$ in acid medium [23] and chromic acid [24].

Kinetic studies on the oxidation of organic compounds catalyzed by various metal ions are considered as a significant field of chemistry because of the role of metals in biological systems [25-32]. One of the important metal catalysts is palladium which is a rare and lustrous silverywhite metal referred to platinum group metals. Catalysis by Palladium is very significant in organic chemistry [33] e.g. medicinal chemistry [34] and the preparation of fine chemicals [35]. It is a versatile metal applied inhomogeneous catalysis. Most studies using palladium as catalyst have 
employed it in the form of palladium(II) chloride [31, 36-38] which exists as $\left[\mathrm{PdCl}_{4}\right]^{2-}$ in acidic media.

The present title deals with the kinetics of oxidation of inositol by hexachloroplatinate(IV) complex in perchlorate solutions in the presence of palladium(II) catalyst. This work aims to study the selectivity of inositol towards HCP in acidic medium, to check the catalytic efficiency of $\mathrm{Pd}(\mathrm{II})$ catalyst and to elucidate a probable oxidation mechanism.

\section{Experimental}

\subsection{Materials}

Reagent grade chemicals and bidistilled water have been employed in the present work. A stock solution of inositol was prepared by dissolving the sample (E. Merck) in bidistilled water. Chloroplatinic acid solution (Johnson Matthey) was freshly prepared by dilution of the original solution with bidistilled water and standardized spectrophotometrically [39]. Sodium perchlorate and acetic acid solutions have been used to study the effects of ionic strength and dielectric constant of the medium, respectively.

\subsection{Kinetic Measurements}

All kinetic measurements were performed under pseudofirst order conditions, where [INOS] $>$ [HCP]. The ionic strength, $I$, of the reaction mixture was adjusted to $1.0 \mathrm{~mol}$ $\mathrm{dm}^{-3}$. The course of the reaction was followed spectrophotometrically by monitoring the decrease in the absorbance of HCP at $\lambda=263 \mathrm{~nm}$, using a temperaturecontrolled Shimadzu UV-VIS-NIR-3600 double-beam spectrophotometer.

It was observed that the oxidation reaction was proceeded very slowly in the absence of $\mathrm{Pd}(\mathrm{II})$ catalyst. The observed rate constants of the catalyzed reaction $\left(k_{\mathrm{C}}\right)$ were obtained from the linear portion of $\ln ($ Abs. $)$ - time plots. These values were the average of at least two independent kinetics runs and were reproducible to within $\pm 3 \%$. Reactions orders were calculated from the slope of $\log k_{\mathrm{C}}$ versus $\log$ (Conc.) plots by varying the concentrations of INOS, $\mathrm{HClO}_{4}$ and $\mathrm{Pd}(\mathrm{II})$ in turn and keeping all other concentrations and conditions constant.

The spectral changes throughout palladium(II)-catalyzed oxidation of inositol by HCP in perchlorate solutions are illustrated in Figure 1. The scanned spectra indicate gradual disappearance of the HCP absorption band with time. Two isosbestic points were also observed in the the spectra.

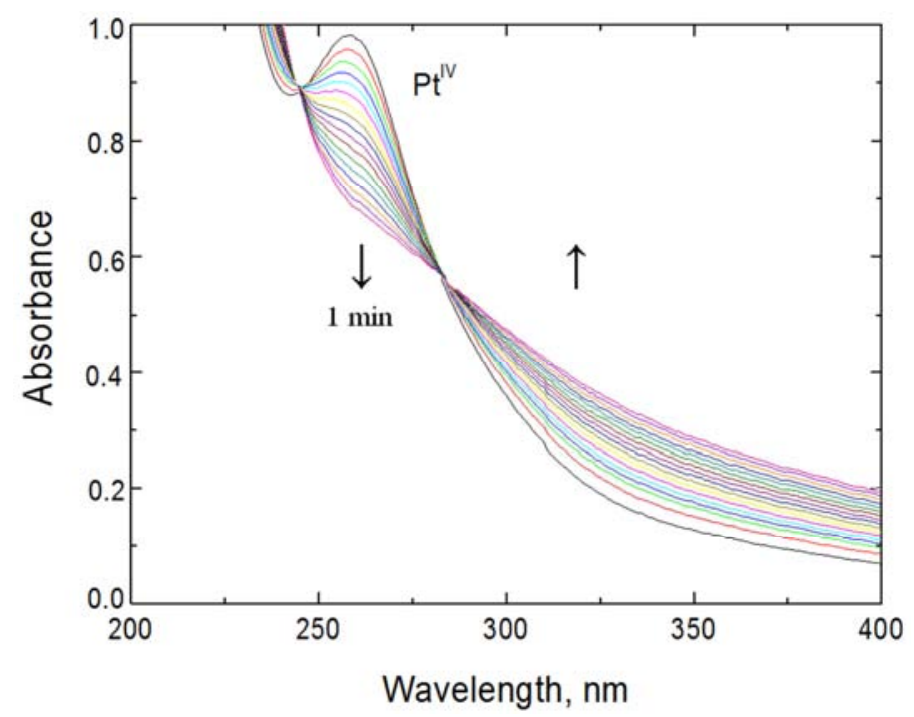

Figure 1. Spectral changes during palladium(II)-catalyzed oxidation of inositol by hexachloroplatinate(IV) in perchlorate solution. [INOS] $=6.0 x 10^{-3},[H C P]$ $=8.0 \times 10^{-5},\left[\mathrm{H}^{+}\right]=0.5,[\mathrm{Pd}(\mathrm{II})]=6.0 \times 10^{-5}$ and $\mathrm{I}=1.0 \mathrm{~mol} \mathrm{dm} \mathrm{m}^{-3}$ at $25^{\circ} \mathrm{C}$.

\section{Results}

\subsection{Stoichiometry and Product Analysis}

Different sets of the reaction mixture containing various amounts of HCP and INOS at fixed acidity, [Pd(II)], ionic strength, and temperature were allowed to react for about 24 h. After completion of the reaction, the unreacted [HCP] was determined spectrophotometrically. The obtained results showed that the reaction stoichiometry is $1: 1$, as represented by the following stoichiometric equation:

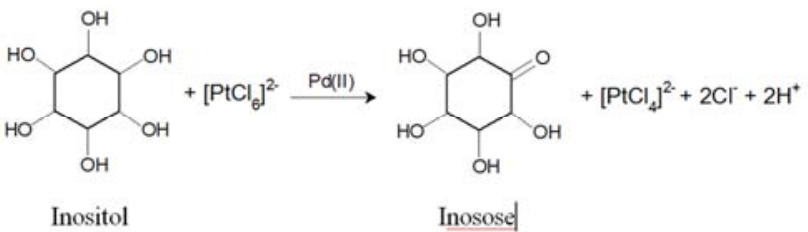

The oxidation product of inositol was identified by both spectral and chemical analyses $[40,41]$ as the corresponding monoketone derivative, namely inosose. Also, the formed $\left[\mathrm{PtCl}_{4}\right]^{2-}$ was confirmed as reported elsewhere [9-15]. 


\subsection{Effect of [HCP]}

The effect of the hexachloroplatinate(IV) oxidant was investigated by varying its concentration in the range of $(2.0$

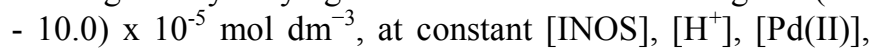
ionic strength and temperature, and measuring the values of $k_{\mathrm{C}}$. The non-variation in $k_{\mathrm{C}}$ at different [HCP] (Table 1) indicates that the order with respect to the oxidant is confirmed to be one.

\subsection{Effect of [INOS]}

The rate constant $\left(k_{\mathrm{C}}\right)$ was determined at various inositol concentrations keeping others constant. The results showed that $k_{\mathrm{C}}$ increases with increasing [INOS] as listed in Table 1. The plot of $k_{\mathrm{C}}$ versus [INOS] were found to be linear with non-zero intercepts indicating fractional-first order kinetics in [INOS] (Figure 2).

\subsection{Effect of $\left[\mathrm{H}^{+}\right]$}

The oxidation rate was measured at constant concentration of INOS, HCP, Pd(II) but with various $\left[\mathrm{H}^{+}\right](0.1-0.9 \mathrm{~mol}$ $\left.\mathrm{dm}^{-3}\right)$. The reaction rate was found to increase as $\left[\mathrm{H}^{+}\right]$ increased with less than unit order as found from the plot of $\log k_{\mathrm{C}}$ versus $\log \left[\mathrm{H}^{+}\right]$(Figure 3).

\subsection{Effect of [Pd(II)]}

The rate of reaction was measured with various concentration of palladium(II) catalyst in the concentration range of $(2.0-10.0) \times 10^{-5} \mathrm{~mol} \mathrm{dm}^{-3}$ at constant other variables. The oxidation rate was found to increase with increasing $[\mathrm{Pd}(\mathrm{II})]$ as listed in Table 1 . The order with respect to $[\mathrm{Pd}(\mathrm{II})]$ was less than unity as found from the plot of $\log$ $k_{\mathrm{C}}$ versus $\log [\mathrm{Pd}(\mathrm{II})]$ as illustrated in Figure 4.

\subsection{Effect of Ionic Strength and Dielectric Constant}

The effect of ionic strength on the oxidation rate was investigated by addition of $\mathrm{NaClO}_{4}$ to the reaction medium at constant other variables. The results showed that the observed rate constant increases with increasing ionic strength, and the Debye-Hückel plot was found to be linear with a positive slope as shown in Figure 5. Also, the effect of dielectric constant $(D)$ of the reaction medium on the oxidation rate was examined by measuring the oxidation rate at different solvent compositions ( $\mathrm{v} / \mathrm{v})$ of acetic acid and water. The rate constant decreased with the decrease in dielectric constant of the solvent mixture, i.e., increase in acetic acid content. The plot of $\log k_{\mathrm{C}}$ versus $1 / D$ was found to be linear with a negative slope as shown in Figure 6.

Table 1. Effect of variation of [HCP], [INOS], [H+ $],[P d(I I)]$ and ionic strength, I, on the observed first order rate constant (kC) in the palladium(II)-catalyzed oxidation of inositol by hexachloroplatinate(IV)in perchlorate solutions at $25^{\circ} \mathrm{C}$.

\begin{tabular}{|c|c|c|c|c|c|}
\hline $10^{5}[\mathrm{HCP}]\left(\mathrm{moldm}^{-3}\right)$ & $10^{3}[\mathrm{INOS}]\left(\mathrm{moldm}^{-3}\right)$ & {$\left[\mathrm{H}^{+}\right]\left(\mathrm{moldm}^{-3}\right)$} & $10^{5}[\mathrm{Pd}(\mathrm{II})]\left(\mathrm{moldm}^{-3}\right)$ & $I\left(\mathrm{moldm}^{-3}\right)$ & $10^{5} k_{\mathrm{C}}\left(\mathrm{s}^{-1}\right)$ \\
\hline 2.0 & 6.0 & 0.5 & 6.0 & 1.0 & 29.2 \\
\hline 4.0 & 6.0 & 0.5 & 6.0 & 1.0 & 28.9 \\
\hline 6.0 & 6.0 & 0.5 & 6.0 & 1.0 & 30.4 \\
\hline 8.0 & 6.0 & 0.5 & 6.0 & 1.0 & 28.9 \\
\hline 10.0 & 6.0 & 0.5 & 6.0 & 1.0 & 27.7 \\
\hline 8.0 & 2.0 & 0.5 & 6.0 & 1.0 & 11.1 \\
\hline 8.0 & 4.0 & 0.5 & 6.0 & 1.0 & 21.0 \\
\hline 8.0 & 6.0 & 0.5 & 6.0 & 1.0 & 28.9 \\
\hline 8.0 & 8.0 & 0.5 & 6.0 & 1.0 & 36.3 \\
\hline 8.0 & 10.0 & 0.5 & 6.0 & 1.0 & 42.0 \\
\hline 8.0 & 6.0 & 0.1 & 6.0 & 1.0 & 8.4 \\
\hline 8.0 & 6.0 & 0.3 & 6.0 & 1.0 & 19.5 \\
\hline 8.0 & 6.0 & 0.5 & 6.0 & 1.0 & 28.9 \\
\hline 8.0 & 6.0 & 0.7 & 6.0 & 1.0 & 35.1 \\
\hline 8.0 & 6.0 & 0.9 & 6.0 & 1.0 & 43.2 \\
\hline 8.0 & 6.0 & 0.5 & 2.0 & 1.0 & 12.3 \\
\hline 8.0 & 6.0 & 0.5 & 4.0 & 1.0 & 21.5 \\
\hline 8.0 & 6.0 & 0.5 & 6.0 & 1.0 & 28.9 \\
\hline 8.0 & 6.0 & 0.5 & 8.0 & 1.0 & 37.1 \\
\hline 8.0 & 6.0 & 0.5 & 10.0 & 1.0 & 45.3 \\
\hline 8.0 & 6.0 & 0.5 & 6.0 & 1.0 & 28.9 \\
\hline 8.0 & 6.0 & 0.5 & 6.0 & 1.5 & 33.0 \\
\hline 8.0 & 6.0 & 0.5 & 6.0 & 2.0 & 35.3 \\
\hline 8.0 & 6.0 & 0.5 & 6.0 & 2.5 & 38.0 \\
\hline 8.0 & 6.0 & 0.5 & 6.0 & 3.0 & 40.1 \\
\hline
\end{tabular}

Experimental Error $\pm 3 \%$ 


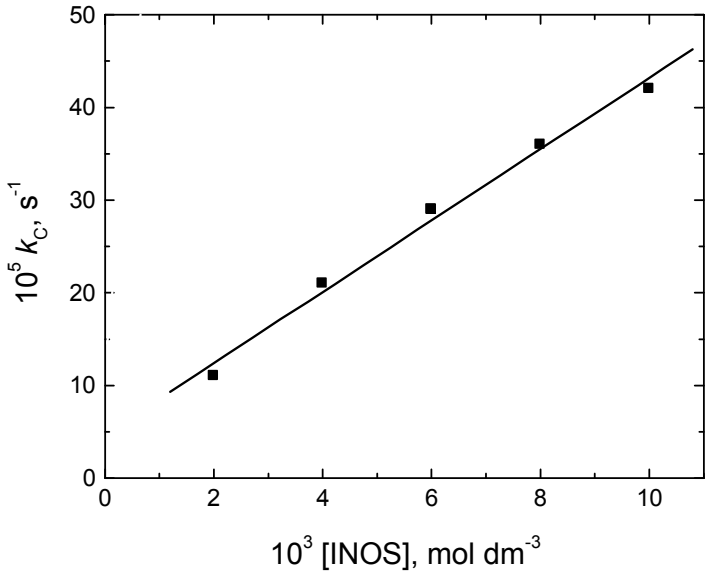

Figure 2. Plot of $k_{C}$ versus [INOS] in the palladium(II)-catalyzed oxidation of inositol by hexachloroplatinate(IV) in perchlorate solution. $[\mathrm{HCP}]=8.0 x$ $10^{-5},\left[H^{+}\right]=0.5,[P d(I I)]=6.0 \times 10^{-5}$ and $I=1.0 \mathrm{~mol} \mathrm{dm}^{-3}$ at $25^{\circ} \mathrm{C}$.

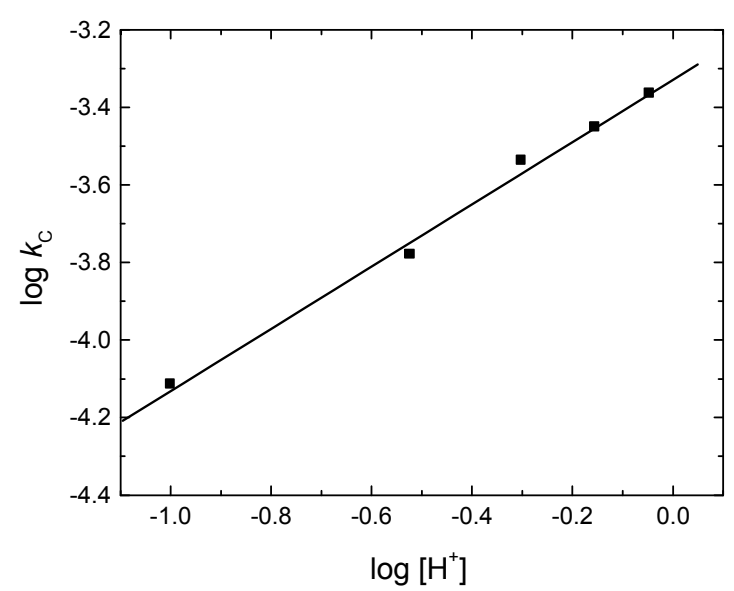

Figure 3. Plot of $\log k_{C}$ versus $\log \left[H^{+}\right]$in the palladium(II)-catalyzed oxidation of inositol by hexachloroplatinate(IV) in perchlorate solution. $[I N O S]=6.0 \times 10^{-3},[\mathrm{HCP}]=8.0 \times 10^{-5},[\mathrm{Pd}(\mathrm{II})]=6.0 \times 10^{-5}$ and $I=1.0$ mol dm $m^{-3}$ at $25^{\circ} \mathrm{C}$.

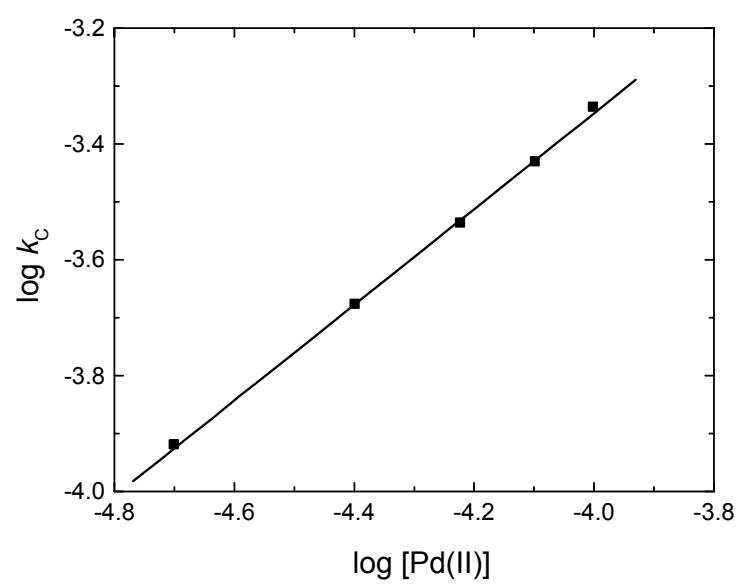

Figure 4. Plot of $\log k_{C}$ versus $\log [P d(I I)]$ in the palladium(II)-catalyzed oxidation of inositol by hexachloroplatinate(IV) in perchlorate solution. $[I N O S]=6.0 \times 10^{-3},[H C P]=8.0 \times 10^{-5},\left[H^{+}\right]=0.5$ and $I=1.0 \mathrm{~mol} \mathrm{dm}^{-3}$ at $25^{\circ} \mathrm{C}$.

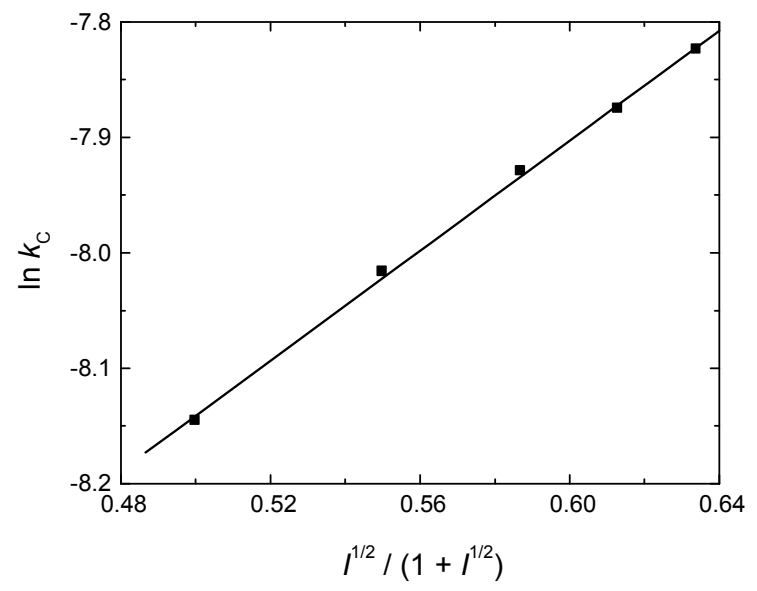

Figure 5. Debye-Hückel plot in the palladium(II)-catalyzed oxidation of inositol by hexachloroplatinate (IV) in perchlorate solution. [INOS] $=6.0 \times 10^{-}$ , $[\mathrm{HCP}]=8.0 \times 10^{-5},\left[\mathrm{H}^{+}\right]=0.5,[P d(I I)]=6.0 \times 10^{-5}$ and $I=1.0 \mathrm{~mol} \mathrm{dm} m^{-3}$ at $25^{\circ} \mathrm{C}$.

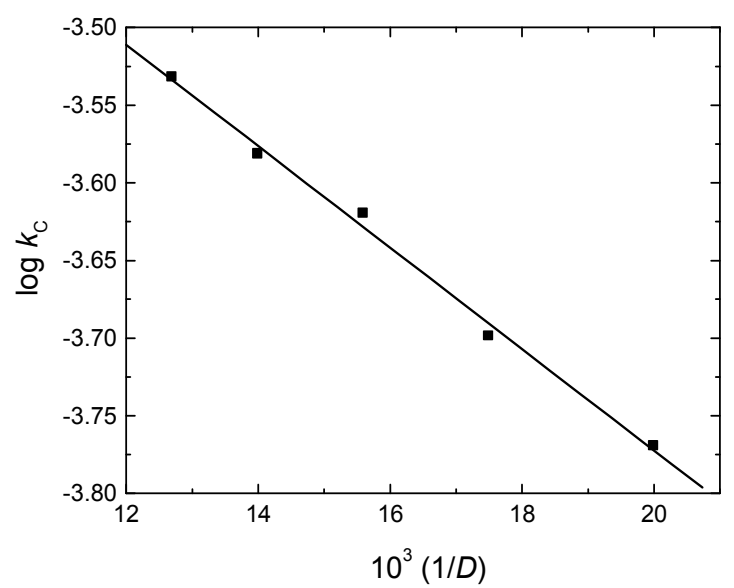

Figure 6. Plot of log $k_{C}$ versus $1 / D$ for the palladium(II)-catalyzed oxidation of inositol by hexachloroplatinate(IV) in perchlorate solution. [INOS] $=6.0$ $\times 10^{-3},[H C P]=8.0 \times 10^{-5},\left[H^{+}\right]=0.5,[P d(I I)]=6.0 \times 10^{-5}$ and $I=1.0 \mathrm{~mol}$ $d m^{-3}$ at $25^{\circ} \mathrm{C}$.

\subsection{Effect of Temperature}

The oxidation rate was were performed at five different temperatures in the range of $288-308 \mathrm{~K}$, at constant concentrations of the reactants. The activation parameters of the second order rate constants $\left(k_{2}\right)$ are calculated using Arrhenius and Eyring plots and are listed in Table 2.

Table 2. Activation parameters of the second order rate constants $k_{2}$ in the palladium(II)-catalyzed oxidation of inositol by hexachloroplatinate(IV) in perchlorate solution. $[\mathrm{INOS}]=6.0 \times 10^{-3},[\mathrm{HCP}]=8.0 \times 10^{-5},\left[\mathrm{H}^{+}\right]=0.5$, $[P d(I I)]=6.0 \times 10^{-5}$ and $I=1.0 \mathrm{~mol} \mathrm{dm}^{-3}$.

\begin{tabular}{llll}
\hline$\Delta \boldsymbol{S}^{\ddagger}, \mathbf{J} \mathrm{mol}^{-1} \mathrm{~K}^{-1}$ & $\Delta \boldsymbol{H}^{\ddagger}, \mathbf{k J} \mathrm{mol}^{-1}$ & $\Delta G^{\ddagger}{ }_{298}, \mathrm{~kJ} \mathrm{~mol}^{-1}$ & $E_{\mathrm{a}}{ }^{\ddagger}, \mathrm{kJ} \mathrm{mol}^{-1}$ \\
\hline-89.12 & 47.46 & 74.41 & 50.11 \\
\hline
\end{tabular}

\subsection{Polymerization Test}

The involvement of free radicals in the oxidation reaction was examined by the polymerization test. The reaction mixture to which a known quantity of acrylonitrile monomer was added initially and was kept for about $6 \mathrm{~h}$. Upon diluting 
the reaction mixture with methanol, there was no white precipitate formed, suggesting absence of free radical intervention during the oxidation reaction. This indicates that the reaction was not routed through free radical path.

\section{Discussion}

The present reaction between inositol and hexachloroplatinate(IV) in perchlorate solution have a stoichiometry of $1: 1$. The reaction exhibited a first order dependence with respect to $[\mathrm{HCP}]$, less than unit order dependences with respect to $[\mathrm{INOS}],\left[\mathrm{H}^{+}\right]$and $[\mathrm{Pd}(\mathrm{II})]$. The observed enhancement of the oxidation rate upon increasing acid concentration with less than unit order dependence suggests that the protonated form of inositol substrate may be considered as the kinetically reactive species in the ratedetermining step, which play the main role in the reaction kinetics. The less than unit order dependences with respect to both inositol and palladium(II) concentrations suggests formation of an intermediate complex between inositol and the active species of $\mathrm{Pd}(\mathrm{II})$ catalyst, $\left[\mathrm{PdCl}_{4}\right]^{2-}$, as reported earlier [31, 36-38]. Complex formation was proved kinetically by the non-zero intercept of the plot of $\left[\mathrm{Pd}^{\mathrm{II}}\right] / k_{\mathrm{C}}$ versus 1/[INOS] (Figure 7). Spectroscopic evidence to support complex formation was obtained from the UV-Vis spectra as the appearance of two isosbestic points as shown in Figure 1.

Owing to the experimental results and the abovementioned arguments, the oxidation mechanism illustrated in Scheme 1 suggests that the protonated inositol combines with $\left[\mathrm{PdCl}_{4}\right]^{2-}$ to form an intermediate complex (C). Such complex slowly reacts with one molecule of HCP to give the oxidation product of inositol with regeneration of the catalyst $\mathrm{Pd}(\mathrm{II})$. Increasing the oxidation rate with increasing both ionic strength and dielectric constant of the reaction medium suggests that the reaction in the rate-determining step occur between two similarly charged ions $[42,43]$, i.e. between the negatively charged complex $(\mathrm{C})$ and $\left[\mathrm{PtCl}_{6}\right]^{2-}$.<smiles>[X]C(=C)C[CH+]C1C(O)C(O)C(O)C(O)C1O</smiles>

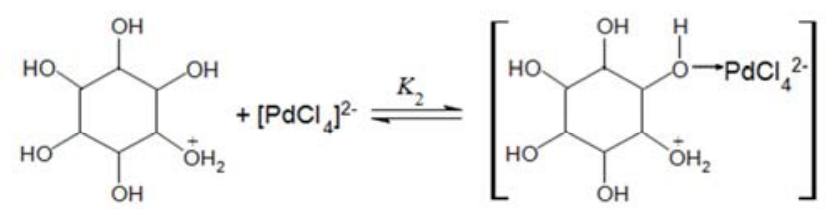

(C)

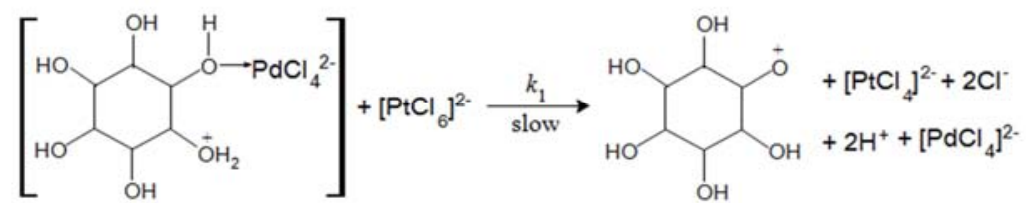<smiles>CC(C)C1C(O)C(O)C(O)C(O)C1O</smiles>

Scheme 1. Mechanism of palladium(II)-catalyzed oxidations of inositol by hexachloroplatinate(IV) in perchlorate solutions.

According to the suggested mechanistic Scheme 1, the relationship between the rate of oxidation and the concentrations of inositol, hydrogen ion, palladium(II) catalyst and hexachloroplatinate(IV) oxidant may be represented by the following rate-law expression,

$$
\text { Rate }=\frac{k_{1} K_{1} K_{2}[\mathrm{INOS}]\left[\mathrm{H}^{+}\right][\mathrm{Pd}(\mathrm{II})][\mathrm{HCP}]}{\left(1+K_{1}\left[\mathrm{H}^{+}\right]\right)\left(1+K_{1} K_{2}[\mathrm{INOS}]\left[\mathrm{H}^{+}\right]\right)}
$$

Under pseudo-first-order conditions, the rate law can be expressed as,

$$
\text { Rate }=\frac{-d[\mathrm{HCP}]}{d t}=k_{C}[\mathrm{HCP}]
$$

Comparing Eqs. (5) and (6) leads to Eq. (7),

$$
k_{C}=\frac{k_{1} K_{1} K_{2}[\operatorname{INOS}]\left[\mathrm{H}^{+}\right][\mathrm{Pd}(\mathrm{II})]}{\left(1+K_{1}\left[\mathrm{H}^{+}\right]\right)\left(1+K_{1} K_{2}[\operatorname{INOS}]\left[\mathrm{H}^{+}\right]\right)}
$$

and with rearrangement it becomes, 


$$
\begin{gathered}
\frac{[\mathrm{Pd}(\mathrm{II})]}{k_{\mathrm{C}}}=\left(\frac{1+K_{1}\left[\mathrm{H}^{+}\right]}{k_{1} K_{1} K_{2}\left[\mathrm{H}^{+}\right]}\right) \frac{1}{[\mathrm{INOS}]}+K^{\prime} \\
\frac{[\mathrm{Pd}(\mathrm{II})]}{k_{\mathrm{C}}}=\left(\frac{1}{k_{1} K_{1} K_{2}[\mathrm{INOS}]}\right) \frac{1}{\left[\mathrm{H}^{+}\right]}+\frac{1}{k_{1} K_{2}[\mathrm{INOS}]}+K^{\prime}
\end{gathered}
$$

where $K^{\prime}=\left(1+K_{1}\left[\mathrm{H}^{+}\right]\right) / k_{1}$.

According to equations (8) and (9), the plots of $[\mathrm{Pd}(\mathrm{II})] / k_{\mathrm{C}}$ against $1 /[\mathrm{INOS}]$, at constant $\left[\mathrm{H}^{+}\right]$, and $[\mathrm{Pd}(\mathrm{II})] / k_{\mathrm{C}}$ against $1 /\left[\mathrm{H}^{+}\right]$, at constant [INOS], should be linear with positive intercepts on $[\mathrm{Pd}(\mathrm{II})] / k_{\mathrm{C}}$ axes. The experimental results satisfied this requirement as shown in Figures 7 and 8, respectively.

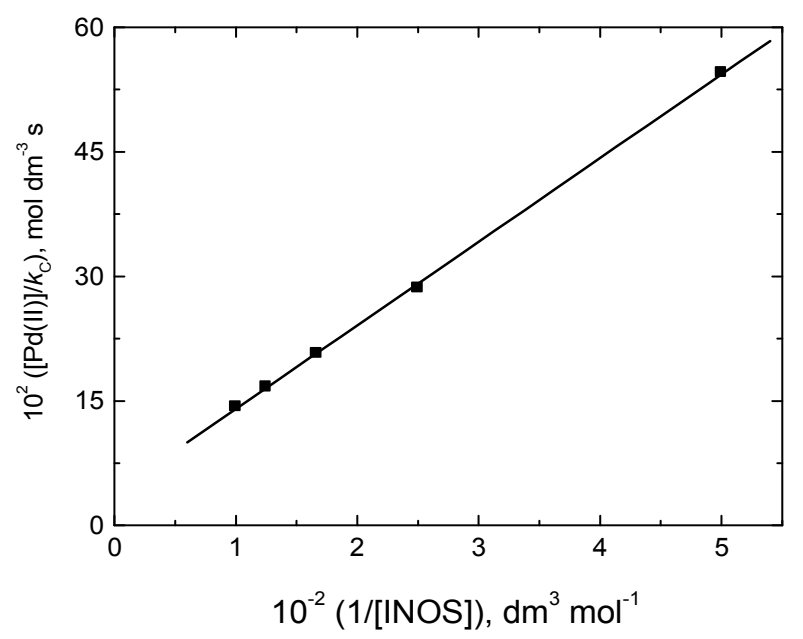

Figure 7. Verification of equation (8) in the palladium(II)-catalyzed oxidations of inositol by hexachloroplatinate(IV) in perchlorate solutions. $[\mathrm{HCP}]=8.0 \times 10^{-5},\left[\mathrm{H}^{+}\right]=0.5$ and $\mathrm{I}=1.0 \mathrm{~mol} \mathrm{dm^{-3 }}$ at $25^{\circ} \mathrm{C}$.

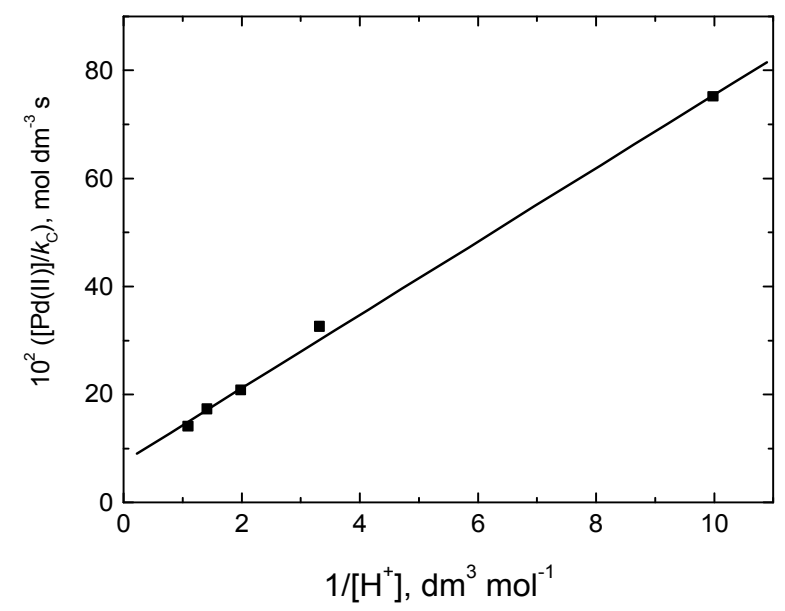

Figure 8. Verification of equation (9) in the palladium(II)-catalyzed oxidations of inositol by hexachloroplatinate(IV) in perchlorate solutions. $[I N O S]=6.0 \times 10^{-3},[H C P]=8.0 \times 10^{-5}$ and $I=1.0 \mathrm{~mol} \mathrm{dm}^{-3}$ at $25^{\circ} \mathrm{C}$.

The activation parameters listed in Table 2 may be interpreted as follows. The obtained negative values of $\Delta S^{\ddagger}$ suggest that the reactions point towards the inner-sphere pathway [44]. The positive values of both $\Delta H^{\ddagger}$ and $\Delta G^{\ddagger}$ confirm endothermic formation of the intermediate complexes and their non-spontaneities, respectively.

\section{Conclusions}

The kinetics of oxidation of inositol by hexachloroplatinate(IV) has been investigated in perchlorate solutions in the presence of palladium(II) catalyst. The reaction was proceeded very slowly in the absence of the catalyst. A probable oxidation mechanism has been suggested. The oxidation product of inositol substrate identified as the corresponding mono ketone, namely inosose.

\section{References}

[1] Keage MC, Kelland MJ, Neidles LR, Warning MJ, ed. (1993) Molecular Aspects of Anticover Drug DNA Interactions, vol. 1, CRC Press, New York, NY, USA.

[2] Lemma K, Sargeson A, Elding LI (2000) Kinetics and mechanism for reduction of oral anticancer platinum(IV) dicarboxylate compounds by L-ascorbate ions. J. Chem. Soc. Dalton Trans. 7: 1167-1172.

[3] Lemma K, Shi T, Elding LI (2000) Kinetics and mechanism for reduction of the anticancer prodrugtrans, trans, trans$\left[\mathrm{PtCl}_{2}(\mathrm{OH})_{2}\left(\mathrm{c}-\mathrm{C}_{6} \mathrm{H}_{11} \mathrm{NH}_{2}\right)\left(\mathrm{NH}_{3}\right)\right]$ (JM335) by thiols. Inorg. Chem. 39: 1728-1734.

[4] Weiss RP, Christian MC (1993) Newcisplatin analogues in development. A review. Drugs 46: 360-377.

[5] Beattie K, Basolo F (1967) Reduction of some platinum(IV) complexes with tris(bipyridine) chromium(II) ion. Inorg. Chem. 6: 2069-2073.

[6] Beattie K, Basolo F (1971) Two-electron inner-sphere reduction of chloropentaammine-platinum(IV) ion by aquochromium(II) ion. Inorg. Chem. 10: 486-491.

[7] Moodley KG, Nicol MJ (1977) Kinetics of the reduction of platinum(IV) by tin(II) and copper(I) in aqueous chloride solutions. J. Chem. Soc. Dalton Trans. 239-243.

[8] Pal B, Sen Gupta KK (2000) Kinetics and mechanism of hexachloroplatinate(IV) reduction by some neutralized alphahydroxy acids in a carbonate-hydrogen carbonate buffer medium, Bull. Chem. Soc. Jpn. 73: 553-560.

[9] Fawzy A (2014) Influence of copper(II) catalyst on the oxidation of L-histidine by platinum(IV) in alkaline medium: a kinetic and mechanistic study. Transition Met. Chem. 39: $567-576$.

[10] Fawzy A (2015) Kinetics and mechanistic approach to the oxidative behavior of biological anticancer platinum(IV) complex towards L-asparagine in acid medium and the effect of copper(II) catalyst. Int. J. Chem. Kinet. 47: 1-12.

[11] Fawzy A, Asghar BH (2015) Kinetics and mechanism of uncatalyzed and silver(I)-catalyzed oxidation of L-histidine by hexachloroplatinate(IV) in acid medium. Transition Met. Chem. 40: 287-295.

[12] Asghar BH, Altass HM, Fawzy A (2015) Transition metal ions-catalyzed oxidation of L-asparagine by platinum(IV) in acid medium: a kinetic and mechanistic study. Transition Met. Chem. 40: 587-594. 
[13] Fawzy A, Zaafarany IA (2015) Kinetic and mechanistic investigation on the zirconium(IV)-catalyzed oxidation of Lhistidine by hexachloroplatinate(IV) in acid medium. Chem. Sci. Rev. Lett. 4: 608-618.

[14] Fawzy A, Zaafarany IA (2015) Mechanistic investigation of copper(II)-catalyzed oxidation of L-asparagine by hexachloroplatinate(IV) in aqueous alkaline medium: a kinetic approach. J. Multidisc. Eng. Sci. Technol. 2: 1038-1045.

[15] Asghar BH, Altass HM, Fawzy A (2016) Silver(I)-catalysis of oxidative deamination and decarboxylation of L-asparagine and L-histidine by platinum(IV) in perchloric acid solutions: a comparative kinetics study. J. Env. Chem. Eng.4:617-623.

[16] Michell RH (2007) Evolution of the diverse biological roles of inositols. Biochem. Soc. Symp. 74: 223-246.

[17] Shen X, Xiao H, Ranallo R, Wu WH, Wu C (2003) Modulation of ATP-dependent chromatin-remodeling complexes by inositol polyphosphates. Science 299: 112-114.

[18] Rapiejko PJ, Northup JK, Evans T, Brown JE, Malbon CC (1986) G proteins of fat cells role in hormonal regulation of intracellular inositol 1,4,5-trisphosphate. Biochem. J. 240:3540

[19] Larner J (2002) D-chiro-inositol -its functional role in insulin action and its deficit in insulin resistance. Int. J. Exp. Diabetes Res.3:47-60.

[20] Kumar YL, Nadh RV, Radhakrisinami PS (2012) Kinetics of oxidation of myo-inositol by potassium periodate in alkaline medium. Asian J. Chem. 24:5869-5872.

[21] Nayak GT, Hadmani CC, Harihar AL (2015) Kinetic and mechanistic investigations of oxidation of myo-inositol by diperiodatocuprate(III) in aqueous alkaline medium. Chem. Sci. Trans. 4:199-207.

[22] Nayak GT, Hadmani CC, Harihar AL (2014) Oxidation of myo-inositol by alkaline permanganate and the effect of alkali metal ion catalysts: kinetic and mechanistic approach. Know Res. 1:33-39.

[23] Kumar A, Rain M (1974) Mechanism of oxidation of cyclohexanehexol (inositol) by quinquevalentvanadium. Int $\mathrm{J}$ Chem. Kinet. 6:15-28.

[24] Santoro M, Caffaratti E, Salas-Peregrin GM, Korecz L, Rockenbauer A, Sala LF, Signorella F (2007) Kinetics and mechanism of the chromic oxidation of myo-inositol. Polyhedron 26:169-177.

[25] Kini AK, Farokhi SA, Nandibewoor ST (2002) A comparative study of ruthenium(III) catalysed oxidation of L-leucine and L-isoleucine by alkaline permanganate. A kinetic and mechanistic approach. Transition Met. Chem. 27: 532-540.

[26] Sumathi T, Sundaram PS, Chandramohan G (2011) A kinetic and mechanistic study on the silver(I)-catalyzed oxidation of L-alanine by cerium (IV) in sulfuric acid medium. Arab J. Chem. 4: 427-435.

[27] Devra V, Jain S, Sharma PD (1994) Kinetics and mechanism of oxidation of glycine, alanine, and threonine by fluoride coordinated bismuth(V) in aqueous $\mathrm{HClO}_{4}-\mathrm{HF}$ medium. Int. J. Chem. Kinet. 26: 577-585.

[28] Fawzy A, Ashour SS, Musleh MA, Hassan RM, Asghar BH (2015) Kinetics and mechanistic approach to the chromic acid oxidation of L-tryptophan with a spectral detection of chromium(III) product. J. Saudi Chem. Soc. in press.

[29] Senagar SKS, Yadav BS (1988) Kinetics and mechanism of copper(II)-catalyzed oxidation of asparagine by sodium Nchloro-p-toluene sulphonamide in alkaline media. J. Indian Chem. Soc. 65: 88-90.

[30] Asghar BH, Altass HM, Fawzy A (2015) Copper(II) catalysis for oxidation of L-tryptophan by hexacyanoferrate(III) in alkaline medium: a kinetic and mechanistic approach. J. Saudi. Chem. Soc. in press.

[31] Fawzy A (2015) Palladium(II)-catalyzed oxidation of Ltryptophan by hexacyanoferrate(III) in perchloric acid medium: a kinetic and mechanistic approach. J. Chem. Sci. In press.

[32] Fawzy A, Ashour SS, Musleh MA (2014) Base-catalyzed oxidation of L-asparagine by alkaline permanganate and the effect of alkali-metal ion catalysts: Kinetics and mechanistic approach, React. Kinet. Mech. Catal. 111: 443-460.

[33] Tsuji J (2004) Palladium reagents and catalysis - New Perspective for the $21^{\text {st }}$ century; $2^{\text {nd }}$ ed, John Wiley \& Sons Ltd: Chichester.

[34] Garrett CE, Prasad K (2004) The art of meeting palladium specifications in active pharmaceutical ingredients produced by Pd-catalyzed reactions. Adv. Synth. Catal. 346: 889-896.

[35] Zapf A, Beller M (2002) Fine chemical synthesis with homogeneous palladium catalysts: examples, status and trends. Top. Catal. 19: 101-109.

[36] Chimatadar SA, Koujalagi SB, Nandibewoor ST (2002) Kinetics of palladium(II) catalyzed oxidation of mercury(I) by iron(III)- 2,2'-bipyridyl complex. Indian J. Chem. 41A:316320.

[37] Singh AK, Jaiswal J, Singh RA, Singh K (2009) Mechanism of palladium(II) catalysis in cerium(IV) oxidation of amines in acidic medium. Asian J. Chem. 21:858-862.

[38] Gligorich KM, Sigman MS (2009) Recent advancements and challenges of palladium(II)-catalyzed oxidation reactions with molecular oxygen as the sole oxidant. Chem. Commun.38543862.

[39] Georgieva M, Andonovski B (2003) Determination of platinum(IV) by UV spectrophotometry. Anal. Bioanal. Chem. 375: 836-839.

[40] Vogel AI (1973) Text book of practical organic chemistry, $3^{\text {rd }}$ ed., ELBS Longman, London, pp. 332 and 679.

[41] Feigl F (1975) Spot tests in organic analysis, 195 pp. Elsevier, New York.

[42] Amis ES (1966) Solvent effect on reaction rates and mechanism, Academic Press, New York, pp. 28; Frost AA, Person RG (1970) Kinetics and mechanism, Wiley Eastern, New Delhi, pp. 147

[43] Laidler K (1965) Chemical Kinetics. McGraw-Hill, New York.

[44] Weissberger A (1974) In Investigation of rates and mechanism of reactions in techniques of chemistry, John Wiley \& Sons (New York: Interscience Publication) pp. 421. 